\title{
NUEVAS HIPÓTESIS SOBRE LA MIEL ES MÁS DULCE QUE LA SANGRE DE DALÍ ${ }^{1}$
}

\author{
IVÁn Moure Pazos \\ Università di Bologna y Fundación Pedro Barrié de la Maza
}

El 10 de febrero de 2011, la Fundación Gala-Salvador Dalí adquiría en Christie's el estudio para La miel es más dulce que la sangre (1926) de Dalí -actualmente desaparecido-. Se trata de una obra iconográficamente compleja, así como crucial en la trayectoria del pintor catalán. El presente artículo pretende ofrecer una visión actualizada del cuadro, en base a los últimos descubrimientos que apuntan al Conde de Lautréamont -pseudónimo de Isidore Ducasse- como posible elemento inspirador y protagonista en la obra.

Palabras clave: Salvador Dalí; La miel es más dulce que la sangre; Conde de Lautréamont; Les Chants de Maldoror.

\section{NEW HYPOTHESES ON DALI''S HONEY IS SWEETER THAN BLOOD}

On 10 February 2011, the Gala-Salvador Dalí Foundation acquired at Christie's the preparatory study for Dalí's Honey is Sweeter than Blood (1926), currently in an unknown location. Iconographically, it is a complex painting and crucial in the development of the Catalan artist's work. This article offers an updated view of the painting, based on recent discoveries that point to the Count of Lautréamont -pseudonym of Isidore Ducasse- as a possible inspirational element and protagonist of the work.

Key words: Salvador Dalí; Honey is Sweeter than Blood; Count of Lautréamont; The Songs of Maldoror.

El 11 de abril de 2011, la Fundación Gala-Salvador Dalí exhibió en el Teatro-Museo Dalí el estudio realizado por Dalí para su óleo La miel es más dulce que la sangre (1926)².

Se trata de una de las obras más polémicas del pintor catalán, por diferentes razones: primero, porque es el estudio previo de su-actualmente desaparecido- La miel es más dulce que la sangre (1927), cuyo rastreo y localización ha generado uno de los episodios más relevantes de la historia del arte ${ }^{3}$; segundo, porque dicha obra ha generado múltiples controversias iconográfi-

\footnotetext{
${ }^{1}$ He de agradecer al profesor D. Antonio Monegal Brancós el haberme animado al desarrollo de la presente investigación durante la disertación de mi tesis doctoral.

2 Subasta de Christie's, Londres, 10 de febrero de 2011, 4.794.215 euros.

3 Dicha obra fue expuesta en el "Saló de Tardor" de Barcelona en 1927 y adquirida por la Duquesa de Lerma. Fue reproducida en el núm. 15 de la revista Ciutat en octubre de 1927 para ilustrar el artículo de Dalí: "Film arte-Film
} 
cas dentro de los ámbitos más especializados, pues en ella nos encontramos ante un nuevo paradigma de la plástica daliniana. Y es que, en efecto, su significado ha sido un enigma -y sigue siéndolo en su totalidad- para los grandes estudiosos de Dalí. La variedad de elementos iconográficos y la disparidad de significados nos sitúan ante una producción, a todas luces, compleja y desbordante. Actualmente, la grata noticia de la adquisición de su estudio por una entidad española, me anima a exponer mis tesis sobre La miel es más dulce que la sangre, toda vez, quisiera rendir un homenaje a todos aquellos que dedicaron sus horas a este complejo jeroglifico pictórico, y que, de una u otra forma, fueron balizando el camino de la presente investigación. A continuación, trataré de ofrecer una síntesis explicativa de lo que -tras años de investigación- he descubierto de la desaparecida La miel es más dulce que la sangre; una explicación conciliadora y ecléctica que se ajusta al complejo mundo de Dalí, y que reivindica una lectura lautreamontiana de algunos elementos de la obra. Postura ésta, que ha ido cobrando mayor relevancia en los últimos años.

Sin lugar a dudas, este enfoque hibridado podrá parecer, cuanto menos, cómodo: sin embargo, al tratar con un artista que peca de una megalomanía desenfrenada, que desborda de influencias, y que gusta de fugas iconográficas, será bueno no precipitarse a emitir juicios erróneos.

Partamos de la premisa de que todas las obras de Dalí son una caterva donde confluyen diversos elementos iconográficos, símbolos, $\mathrm{y}$, por lo tanto, significados. Ni siquiera, en su faceta de ilustrador para obras literarias, el autor opta por la representación textual de los diversos pasajes, antes bien, lo que busca es alterar el paralelismo semántico y estructural entre texto e imagen para romper con las normas de correspondencia sígnica establecidas. Es así como, a través de pócimas paranoico-críticas, el artista puede hacer confluir en una misma obra a Freud, Lorca, Napoleón o al mismísimo Ludwig II de Baviera. Desde este prisma heterodoxo, creemos, debe abordarse la obra que nos ocupa. Desde un posicionamiento mixto, abierto y plural.

Las diferentes hipótesis sobre el simbolismo de la obra han ocupado gran parte de la literatura crítica sobre el pintor. Han corrido ríos de tinta para tratar de desvelar el significado de todos esos elementos excesivos y barroquizantes que salpican la obra daliniana. Se ha hablado de Buñuel, de Lorca, o incluso de Picasso para explicar La miel es más dulce que la sangre. También se ha remitido al propio patrimonio afectivo del pintor: a su pulsión psicoanalítica y sus traumas de identidad para descifrar los diferentes elementos del cuadro. Sin embargo, poco se ha citado al Conde de Lautréamont y su obra Les Chants de Maldoror (1868), como uno de los artífices del óleo a tratar; una de las obsesiones más absorbentes -junto a Lorca y Buñuel- del Dalí inicial, y que en feliz connubio con éstos, emulsionará en La miel es más dulce que la sangre, así como también, en el estudio del mismo nombre.

En los últimos años, han aparecido varias investigaciones que tratan de vincular la obra daliniana con el poeta francés ${ }^{4}$. En 2004, con motivo del año Dalí, surgirán nuevas y refrescantes aportaciones en torno a la figura del pintor y su obra. Más allá de biografías tediosas, estudios trillados, o anécdotas mediáticas, afloran un sinfín de estudios centrados en el Dalí más complejo e intelectual. Tasar la verdadera magnitud de un artista tan versátil y polimórfico, pasaba directamente por Lautréamont, y muchos así lo percibieron. La primera autora en comprenderlo fue Silvia Muñoz D'Imbert, en su estupendo artículo "Les Chants de Maldoror: la construcción

\footnotetext{
antiartístico". Desde entonces, permanece en paradero desconocido. La última noticia que se tiene del cuadro es que -según Oriol Anguera- se encontraba en manos de Coco Chanel.

${ }^{4}$ A continuación reseñamos algunas alusiones que, aunque sucintas y epidérmicas, esbozan ya el vínculo DucasseDalí. Por orden cronológico se resaltan las siguientes páginas de libros: FoRNÉs, 1985: 91. RoJAS, 1985: 234-258. Hubert, 1988: 205-209. SÁNCHEZ Vidal, 1988: 281-285. GibSON, 1997: 398-405; 1999: 125-126. RAINWATER, 1997: 26. Ramírez, 2002: 60. Cirlot VAlenZuela, 2004: 11.
} 
de la máquina de lectura”, para el catálogo Dalí: afinidades electivas (2004)5, en el cual se esclarecen algunas de las pautas básicas para esclarecer este diálogo interartístico:

"Sin duda observando los grabados de Les Chants de Maldoror, nos hallamos frente al encuentro de la máquina pictórica de Dalí y la máquina de lectura de Ducasse, las cuales, habiendo traspasado sus propios límites, han conseguido unirse en otro nivel, metalingüístico y metapictórico, en el que se lleva a cabo la gran revelación radical de la imagen"6.

La relación Ducasse-Dalí comenzaba a desgajarse cobrando protagonismo en los mejores repertorios iconográficos del momento. Las alusiones de Félix Fanés ${ }^{7}$, Agustín Sánchez Vidal ${ }^{8}$ o Dawn $\mathrm{Ades}^{9}$, aunque someras, fueron sintomáticas de este empeño.

No tardarían en aparecer estudios específicos sobre la filiación daliniana con Lautréamont. En esta línea, se sucedieron -con mayor o menor fortuna- diversos artículos, como el "Salvador Dalí a golpe de Lautréamont" (2006), de Raúl Herrero ${ }^{10}$, en el que se enumeran algunos de los vínculos formales entre Dalí y Ducasse, o la alusión ficcionada sobre Dios que Fernando Butazzoni realiza en su "Luz de arriba, luz de abajo" (2006) ${ }^{11}$. En otra categoría, se inscribe el trabajo que, desde hace algún tiempo, viene desarrollando Pilar Parcerisas en torno a este diálogo, y que materializará en su magistral artículo "Dalí y Ducasse. La sombra de Maldoror" (2010); una revisión de su conferencia "Dalí et Lautréamont" para el VIII Colloque international sur Lautréamont (2006), ofrecida esta vez para el actual catálogo de la exposición Salvador Dalí. Les Chants de Maldoror. 1934'12.

En dicho artículo, Parcerisas establece una serie de atrevidas e ingeniosas interrelaciones entre Lorca, Maldoror, Lacan y Dalí, para esclarecer el diálogo entre Lautréamont y el pintor: "Será preciso retener esta imagen paranoica cuádruple: ¡Dalí y Lorca, Maldoror y Olé!”13. Para el mismo catálogo, y desde una óptica más formalista, queremos reseñar los trabajos de Juliette Murphy, "Les Chants de Maldoror: documentación y proceso creativo" (2010) $)^{14}$, y de Elisa María Díaz González, "Aguafuerte y Heliograbado: consideraciones en torno a Les Chants de Maldoror" $(2010)^{15}$, en los que se deja constancia rigurosa de todos aquellos aspectos formales relativos a la obra del pintor (documentación, procesos creativos, técnicas...).

Ya en pleno 2011, y en la misma línea interpretativa, caben resaltarse los trabajos de Iván Moure Pazos: El bestiario del conde de Lautrémont: la invocación daliniana; "Víctimas y verdugos en las ilustraciones de Les Chants de Maldoror de Dalí"; y "Sobre el Conde de Lautréamont y el arte surrealista", a los que se hará referencia continuada a lo largo de este artículo ${ }^{16}$.

Como vemos, en los últimos años, han aflorado varios estudios que afianzan el vínculo entre Lautréamont y Dalí, un vínculo que ha dado lugar a nuevas y renovadas hipótesis sobre

\footnotetext{
5 Muñoz D'ImBert, 2004: 351-415.

6 MuÑoz D'IMBERT, 2004: 363.

7 FANÉS, 2003: 29-31.

8 SÁnchez Vidal, 2003: 31-38.

9 Más concretamente, me refiero al anónimo, H.H., 2004: 208-219.

10 Herrero, 2006: 216-218.

11 Butazzoni, 2006: 181-186.

12 Parcerisas, 2010: 133-139. Si bien éste parece ser el texto definitivo, lo cierto es que, en gran parte de la obra de Pilar Parcerisas, es común el acercamiento a Lautréamont desde el surrealismo o Dalí. A continuación enumeramos las páginas salpicadas por la sombra del conde: 2004a: 28-29; 2004b: 113; 2006: 151-154; 2009: 27-37.

13 Parcerisas, 2010: 138.

14 Murphy, 2010: 139-144.

15 Díaz GonzÁlez, 2010: 145-150.

16 Moure Pazos, 2011a; 2010: 225-239; 2011b, s/p (edición electrónica).
} 
La miel es más dulce que la sangre y su estudio. Lo que sigue, pretende esclarecer el enigma de este sensacional cuadro, a fin de comprender que una lectura lautreamontiana vendría a enriquecer y complementar el predominante enfoque oficial o, si se quiere, lorquiano, de la obra daliniana.

\section{Nuevas hipótesis sobre La miel es más dulce que la sangre}

Sabemos por Ian Gibson que Dalí leyó a Lautréamont en la residencia de estudiantes de Madrid, probablemente por influjo directo de Lorca, o indirecto de Rubén Darío:

"Lorca -como Dalí, apasionado discípulo de Darío en su juventud- tenía un ejemplar de Los raros, y en Impresiones y paisajes (1918), su primer libro, había tomado prestada la evocación que hace Rubén de los perros de Lautréamont, perros que ladran a la muerte bajo la luz de la luna. Es posible que Dalí hubiera leído Los raros antes de llegar a Madrid y descubierto allí por sí mismo a Lautréamont. Si no fue así, tal vez Lorca le habló del texto del nicaragüense. Lo que parece seguro, de todas maneras, es que Dalí leyó Los cantos de Maldoror en la Residencia, donde llegó a identificar a Lorca, el tentador, con el héroe epónimo y rebelde del libro de Ducasse"17.

Sobre ello, vuelve a insistir Javier Pérez Andújar: "En su segunda estancia, Dalí encontraría a los alumnos de la Residencia deslumbrados por los Cantos de Maldoror de Lautréamont, un libro del que el grupo surrealista francés se había hecho banderizo" 18 .

Por consiguiente, hemos de iniciar esta investigación considerando que Dalí ya conocía la obra de Lautréamont con anterioridad a la ejecución de La miel es más dulce que la sangre ${ }^{19}$, consumación, como sabemos, de un estudio previo del mismo nombre [figs. 1-2]. Por ello, no ha de sorprendernos que el título del cuadro haya sido puesto en relación con el canto segundo del poeta francés: "O mathématiques sévères, je ne vous ai pas oubliées, depuis que vos savantes leçons, plus douces que le miel, filtrèrent dans mon coeur, comme une onde refraîchisante", que nos muestra, de manera clarividente, la toma daliniana de Les Chants de Maldoror.

El primero en advertir sobre esta extraña coincidencia entre el título del cuadro y la obra de Lautréamont ha sido Agustín Sánchez Vidal en su Buñuel, Lorca, Dalí: el enigma sin fin (1988):

"Sospecho, incluso, que la expresión más dulce que la miel sufre un cambio de sentido en contacto con el poema y el personaje de Ducasse, conde de Lautréamont [...] Maldoror entona un cántico a las matemáticas, cuyo control frío y exacto contrapone a la pasión de vísceras y arterias $[\ldots]]^{י 20}$.

\footnotetext{
17 GiBSON, 2004: 132-133.

18 PÉReZ ANDÚJar, 2003: 101.

19 Descharnes, 1984: 76.

20 SÁNCHEZ VIDAL, 1988: 282.
} 


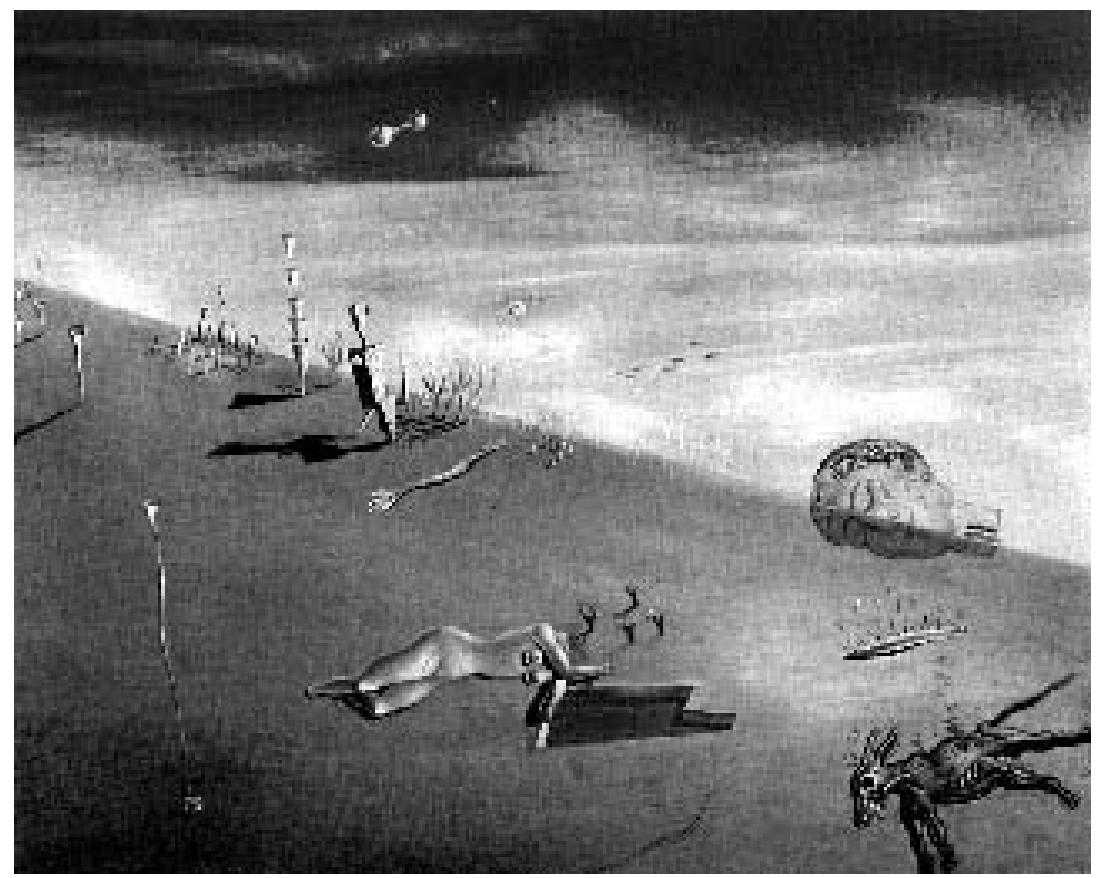

Fig. 1. Dalí. Estudio para La miel es más dulce que la sangre. 1926. Fotografía de época.

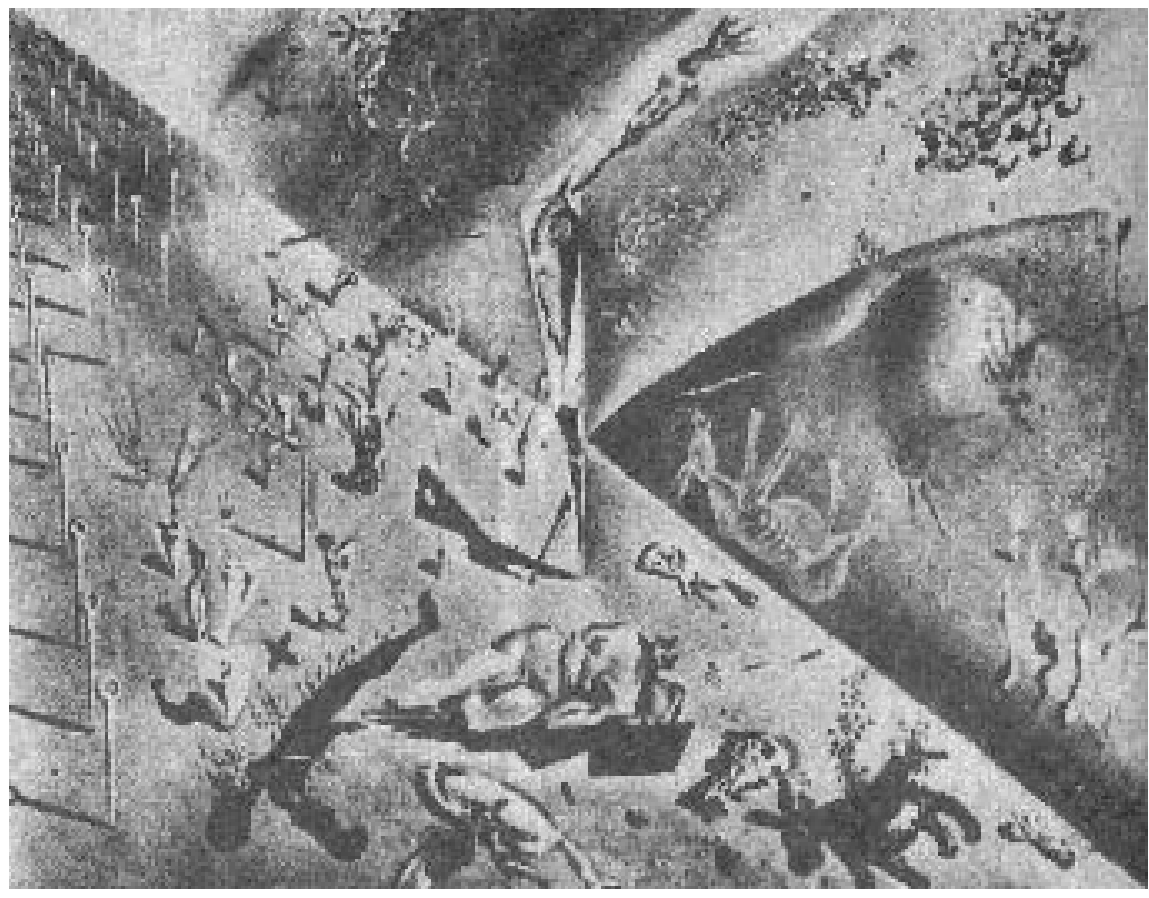

Fig. 2. Dalí. La miel es más dulce que la sangre. 1927. Col. Particular.

Arch. esp. arte, LXXXV, 338, ABRIL-JUNIO 2012, 181-192, ISSN: 0004-0428 
Esta teoría ha sido secundada y desarrollada con posterioridad por autores como Félix Fanés $^{21}$, Pilar Parcerisas ${ }^{22}$ e Iván Moure ${ }^{23}$.

Sabiendo esto, pasemos al estudio iconográfico del cuadro. El óleo es un Horror vacui de elementos dispuestos caóticamente sobre dos triángulos rectángulos que representan el ámbito terrestre y el ámbito aéreo. Sobre la tierra, nos encontramos con las cabezas decapitadas de Lorca y Dalí, que son una de las bases fundamentales sobre la que se sustenta la teoría lorquiana sobre La miel, llevada a cabo por Rafael Santos Torroella en su estupenda tesis La miel es más dulce que la sangre: las épocas lorquiana y freudiana de Salvador Dali (1984) ${ }^{24}$. Sin embargo, esto no es tan sencillo como parece. A tan sólo un año de la aparición de la revolucionaria tesis, Carlos Rojas nos advertía en el Mundo mítico y mágico de Salvador Dalí de lo complejo de este asunto. Según el autor, Dalí identificaba a Lorca con Maldoror, el héroe de la novela de Lautréamont, proponiendo una argumentación conciliadora entre el universo lorquiano y el lautreamontiano, en ocasiones -nos aclara- "mimético": "La poesía de Lautréamont se cruza con la de Lorca, al igual que el perfil del poeta lo hace con el de Dalí [...]"25. Años más tarde, tanto Agustín Sánchez Vidal ${ }^{26}$, como Ian Gibson volverán a apostillar sobre las teorías miméticas de LorcaMaldoror: "Todo indica que Lorca-Maldoror vuelve de Cadaqués enamorado de Dalí" 27. De esto, podremos deducir que no se sostiene una explicación únicamente lorquiana u "oficial" de la obra, antes bien, se impone una argumentación hibridada donde la propia vivencia del artista, su patrimonio afectivo y psicoanalítico, se mezcla con su querencia por los grandes artistas y poetas europeos. En base a estas afirmaciones, debemos valorar la hipótesis de que Dalí conciba a Lorca como genotipo de Maldoror.

Pero prosigamos al estudio del cuadro. No es ninguna novedad afirmar que Dalí dedicó gran parte de su obra escrita y pictórica - sobretodo su obra temprana y meridiana ${ }^{28}$ - a rendir tributo al conde de Lautréamont. Muestras incuestionables de esta querencia son sus cuarenta y dos aguafuertes para ilustrar Les Chants de Maldoror (1934) ${ }^{29}$, el retrato del poeta Portrait imaginaire de Lautréamont á 19 ans, obtenu par la méthode paranoiaque critique (1937), y un sinfín de obras maestras, entre las que destacaré, en sucinto prontuario, su Cannibalisme de la mante religieuse de Lautréamont (1934), así como su célebre Homenaje a Lautréamont (1945) ${ }^{30}$. En ellas, Dalí incide en el emblema surrealista por antonomasia extraído del Canto VI de Les Chants: "Il est beau comme comme la recontre fortuite sur une table de dissection d'une machine à coudre et d'un parapluie" ${ }^{\prime 31}$. A partir de entonces, un aluvión de paraguas y máquinas de coser serán representados, no sólo por Dalí, sino por el total orbe surrealista, de manera compulsiva como

${ }^{21}$ FANÉs, 2003: 29. “[...] que el conocido título del cuadro La miel es más dulce que la sangre es una cita de los Cantos $[\ldots]$...

22 ParCerisas, 2010: 133. "Lautréamont y el personaje de Maldoror están presentes tanto en la literatura como en la plástica de Dalí, quien une la paranoia de Lídia de Cadaqués y la de Ducasse en el título de la pintura dedicada a Lorca La miel es más dulce que la sangre [...]”.

23 Moure Pazos, 2011a: 118.

24 Santos Torroella, 1984. Donde se establece la "época lorquiana" entre los años 1926 y 1929. A modo de síntesis, consultar, del mismo autor: 2005: 326-331.

25 ROJAS, 1985: 256-258.

26 SÁNCHEZ VIDAL, 1988: 282.

27 GIBSON, 1999: 126.

${ }^{28}$ Por producciones tempranas, nos referimos a las surgidas entre los años 20 y 40, por meridianas a las realizadas en los años 50, y por finales o de madurez a las tres últimas décadas.

29 LAUTRÉAMONT, 1934.

${ }^{30}$ Las referencias en la obra de Dalí al Conde son innúmeras y casi inabarcables. Para un acercamiento más completo de esta traslación se recomienda consultar el glosario de mi tesis doctoral: Moure PAzos, 2011a: 287-310.

31 LAUTRÉAMONT, 1988: 462. 
bandera identitaria del istmo surreal ${ }^{32}$. Pues bien, La miel es más dulce que la sangre es, hasta el momento, la primera obra pictórica en mostrarnos la aguja de coser ducassiana alusiva al célebre pasaje de Les Chants. Estamos ante el nacimiento de una emblemática que será representada hasta la saciedad en toda su producción posterior, tanto pictórica como escrita ${ }^{33}$. Por lo tanto, $L a$ miel es más dulce que la sangre catapultará el motivo iconográfico de la aguja y la máquina de coser a edad temprana, incluso, antes de que los grandes surrealistas parisinos se lancen a la representación descontrolada de esta emblemática. Dalí había creado un lenguaje codificado de temáticas ducassianas. Un código cifrado. Un alfabeto iconográfico. Había aflorado el estereotipo lautreamontiano.

Tal precocidad y originalidad, quizás sea la parte más querida y reseñada por los grandes teóricos del surrealismo -entre ellos André Breton- quien, recordemos, atacará la obra meridiana y final del pintor tachándola de previsible y poco original ${ }^{34}$.

Pero continuemos analizando el estupendo anecdotario de imágenes simbólicas que nos brinda La miel es más dulce que la sangre. Dalí salpica su cuadro con diferentes cuerpos putrefactos. Vemos un burro en descomposición tendido sobre el suelo, el mismo burro que, dos años después, nos encontraremos en Un Chien Andolu (1929). También vemos a un tiburón, sobre el que todavía no se ha emitido ninguna hipótesis y que, quizás, pudiéramos poner en relación con el Canto II de Les Chants, donde Maldoror se aparea con la hembra del escualo. De todos modos, cabe ser cautos y afirmar que esto es una mera conjetura, ya que no existe documentación al respecto que corrobore esta identificación.

Levantamos la vista, y en el extremo superior derecho nos encontramos con esos espermatozoides alados que atraviesan el cielo del cuadro, y que, de manera clara, han sido puestos en relación con los peligros fecundadores del Canto II de Les Chants de Maldoror ${ }^{35}$. El pasaje de Lautréamont es uno de los más sencillos de la obra: el hombre es perseguido por el fantasma de la conciencia, un ser misterioso y sin rostro. De él, Lautréamont sólo nos dirá que es amarillo.

32 Para más información consultar: Moure PAzos, 2010: 225-239; 2011b: s/p (edición electrónica).

33 DALí, 2003: 1189-1199. Esta primera acometida cinematográfica se desenvuelve en un ambiente de pesadilla protagonizada por Bobo, un errabundo marinero que tras matar a un hombre se refugia en una tasca. Una vez dentro, se sumerge en una sucesión de alucinaciones lautreamontianas enumeradas cuidadosamente por Dalí. En la primera, Bobo contempla atónito una maraña de caóticos cuerpos interconectados por membranas. Inesperadamente, una cuchara irrumpe en escena para tocar el ojo de esa masa informe al tiempo que los cuerpos se contraen como si fuesen un mismo organismo. Aturdido, el marinero intenta salir de la pesadilla; es entonces cuando aparece ante él una mesa de disección con su respectiva máquina de coser y paraguas. A este punto tiene lugar la alucinación número dos, en la cual dos personajes simulan una calavera virtual. Una calavera que en el delirio número tres se convierte en armazón de múltiples seres repugnantes. No pudiendo soportar tal visión, Bobo pierde el control y sale a la calle donde la lluvia se convierte en una perspectiva infinita de agujas de máquina de coser. Sin más dilación aparecen en el cielo neblinoso gigantescos paraguas luminiscentes y Bobo reaparece en una plaza presidida por una enorme máquina de coser que tricota ojos. El silogismo es claro, la navaja buñuelesca vertida a la aguja ducassiana. Una metáfora de la nueva visión surreal representada a través de la salvaje mutilación óptica.

${ }^{34}$ SÁnCHEZ VIDAL, 2007: 12-15. "Dentro de los lugares comunes o prejuicios antidalinianos, tampoco resulta rara la escisión entre un Dalí bueno y otro malo, como el colesterol. El primero sería el auténtico, creativo, trasgresor, que suele restringirse al período en que es aceptado por André Breton, más o menos entre 1928 y 1936. Y el malo sería, a partir de los años cuarenta, una especie de renegado, vendido al dólar y al franquismo, dedicado a pintar Cristos y Madonnas como un descosido. Desahuciado, entonces, por la autoproclamada intelligentzia y otros burócratas de la alta cultura, se le acusa de practicar un surrealismo degradado, de garrafa. Y se pretende convertir su obra, sin apenas matices, en algo banal, una especie de barraca de feria del subconsciente, suponiéndosele repetitivo y previsible, demasiado previsible: relojes blandos, muletas erectas, huevos fritos voladores..., cosas así" -y posteriormente- "Sucede que demasiadas veces se pasa por alto, se perdona o incluso se elogia a Marcel Duchamp o a Andy Warhol todo aquello que se reprocha a Dalí. Quizá porque siempre ha gozado de mejor prensa el estreñimiento calvinista que el dispendio iconográfico de las culturas católicas y latinas".

${ }^{35}$ Moure Pazos, 2011a: 141. 
El hombre no puede escapar a sus actos y Lautréamont ejemplifica su condena a través de la representación de un universo bosciano: el cielo tormentoso es tomado por legiones de pulpos alados que asemejan cuervos, para más adelante, como en un fotograma, fundirse en una cortina de espermatozoides voladores ${ }^{36}$.

Sobre estas últimas criaturas se ha especulado mucho, siendo motivo de disputa entre los diferentes especialistas en Dalí. Para Félix Fanés estos seres son "bichitos y formas microbianas" ${ }^{37}$, para Dawn Ades son "lechos marinos" 38 , y para Beatriz Fernández Ruiz "es impensable no darles un valor sexual" 39 . Teniendo en cuenta el gran peso intelectual de estos teóricos, creo que debo explicar los porqués de mi identificación. Los espermatozoides alados aparecen en toda la producción daliniana del veintisiete. Buena muestra de ello son sus óleos: Aparato y mano (1927) -donde el espermatozoide alado reaparece en primer término- y Cenicitas (1927-28) ${ }^{40}$. Creemos que la nítida aparición del espermatozoide alado en Aparato y mano es, de por sí, una pista explicativa de las criaturas aladas que asolan La miel es más dulce que la sangre. Sin embargo, la auténtica piedra rosetta que nos permitirá identificar, con total certeza, estos espermatozoides alados, es la lámina realizada por Yves Tanguy para ilustrar el Les Chants de Maldoror acaudillado por André Breton en 1938 [fig. 3] ${ }^{41}$. En ella Tanguy representa el pasaje maldororiano, e introduce la figura del espermatozoide alado como activador de ese mundo onírico, de la misma forma que años antes había realizado Dalín ${ }^{42}$.

Esa "atmosphère extra-littéraire" 43 o si se quiere "l'expresion d'une révélation totale qui semble exceder les posibilités humaines" ${ }^{4}$, son tomadas por Tanguy como pauta ejecutora de su obra, canibalizando en filigrana, el motivo daliniano de la amenaza fecundadora como prolongación de ese hipermundo ducassiano ${ }^{45}$. No cabía duda, la relación entre La miel es más dulce que la sangre y la lámina de Tanguy era incuestionable. A partir de entonces, los cielos dalinianos se convertirán en la morada predilecta de esos visitantes que, desde las alturas, contemplan ese paisaje destronado de belleza, de agujas que se clavan en una tierra extraña y lunar.

36 LAUTRÉAMONT, 1988: 232.

37 FANÉs, 1999: 86. Referido a La miel, "En el triángulo de la derecha, en cambio, lo que abundan son bichitos y otras formas microbianas $[\ldots] "$ ".

38 ADES, 2004a: 92. "La familiaridad de Dalí con Yves Tanguy también es evidente en relación con las siluetas en el aire y la ambigüedad de un paisaje que también podría ser un lecho marino".

39 FernándeZ Ruiz, 2004: 175-176. "En 1927, mientras hace el servicio militar en Figueras, se hace amigo de otro recluta que sabe leer y escribir pero es completamente inculto. Dalí le hace leer textos surrealistas que son probablemente sus primeras lecturas, pero él responde con una espontaneidad y una creatividad que maravillan al pintor [...]. Por ejemplo, después de un largo silencio, exclamó 'Hay un falo volador'. Dalí había estado obsesionado por la imagen de un dedo volante, que relacionaba con el aspecto de su propio pulgar sostenido en la paleta [...]. Es impensable entonces no dar valor sexual a algunas imágenes que aparecen en cuadros como Cenicitas: dedos volantes, cabezas y alas de pájaro $[\ldots]$ ”.

${ }^{40}$ Moure Pazos, 2011a: 141.

${ }^{41}$ Cuatro años después de que Dalí ilustrara la obra de Lautréamont, André Breton reúne al grueso de la pléyade surrealista para hacer lo propio en otra edición de lujo. La obra se encuentra en la Sala Y de la Biblioteca Nacional de Francia bajo grandes medidas de seguridad. Actualmente, el acceso al original es imposible, aunque, por suerte, se puede consultar una copia en microfilm en la sala de reproducción. De esta copia fue extraída la lámina del presente artículo. Vid. LAUTRÉAMONT, 1938.

42 Moure Pazos, 2011a: 142.

43 BRETON, 1938: 10.

44 BRETON, 1938: 10

45 Ades, 2004b: 304. MAs Peinado, 2003: 67. Ambos autores han subrayado la relación Dalí-Tanguy. Lo sorprendente es que no se remita a la ilustración de Tanguy para Les Chants de Maldoror, en la que se identifica a estos seres con los espermatozoides alados. 


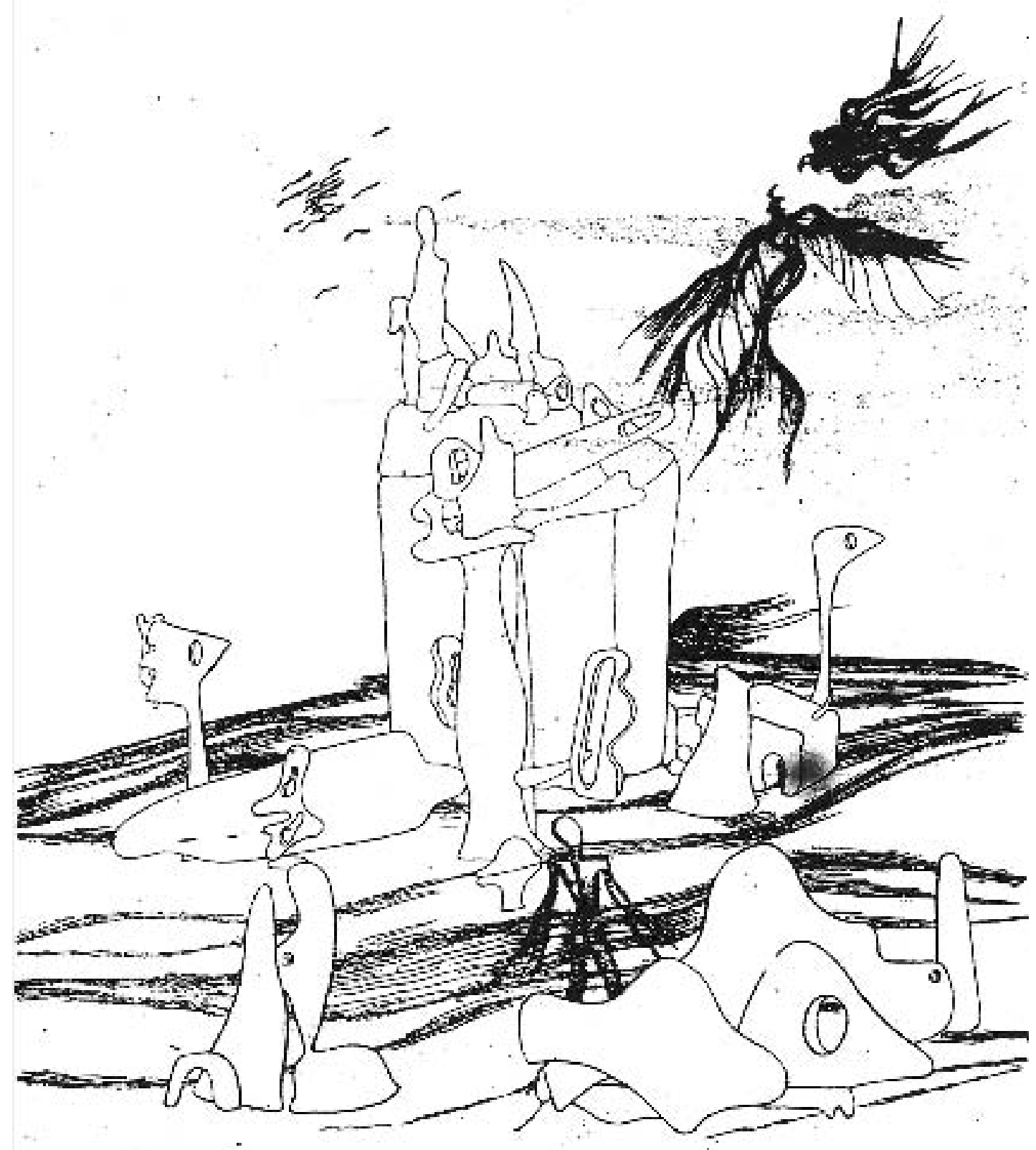

Fig. 3. Les Chants de Maldoror ilustrado por Yves Tanguy. Pasaje de los espermatozoides alados, localizados en el extremo superior izquierda. 1938. Col. BnF. 


\section{Conclusiones}

Iniciábamos este artículo hablando de la complejidad iconográfica de una obra tan escurridiza como La miel es más dulce que la sangre y su estudio. También incidíamos en la necesidad de abordarla desde una perspectiva iconográfica permeable a múltiples interpretaciones y lecturas. Un prisma conciliador y ecléctico donde tuviera cabida Lorca, Buñuel y, no en menor medida, el Conde de Lautréamont. Después de estas páginas, parece ineludible constatar ese entrecruzamiento entre lo leíble de la poética lautreamontiana y lo visible de la plástica daliniana. Como una traslación etílica, el emblema verbal del Conde ha germinado -cincuenta años después- en una suerte de ricas emulsiones pictóricas, de las cuales La miel parece erigirse como la primera y originaria. Estas han resultado ser el principal alimento, no sólo de Dalí, sino del total orbe surrealista. Sabemos que el dardo envenenado de Ducasse ha alcanzado a gran parte de los creadores de aquel París ansiado de nuevas propuestas, pero parece un hecho constatado que Dalí se adelantase a la representación de esta emblemática todavía en suelo español.

Las nuevas corrientes interpretativas que señalan a Lautréamont como figura referencial en La miel es más dulce que la sangre, han ido ganando terreno en la última década. La evidencia del título del cuadro, las teorías miméticas de Carlos Rojas, Agustín Sánchez Vidal y Ian Gibson, o los diferentes elementos lautreamontianos que comportan la obra (agujas de coser, tiburones, y espermatozoides alados) son evidencias de este empeño. Sin embargo -como en todo Dalí-, sería un error realizar una lectura ortodoxa o únicamente lautreamontiana de la obra, pues, como sabemos, Dalí juega con diversos elementos iconográficos que gusta de entreverar. Por lo tanto, este artículo no ha pretendido agotar a Dalí y su obra, sino exponer los últimos desvelos iconográficos sobre La miel, que, en este caso, han resultado ser esencialmente lautreamontianos.

La miel es más dulce que la sangre es, por consiguiente, el primer gesto de Dalí para con Lautréamont. A partir de entonces, la presencia de éste en la obra del pintor se convertirá en una constante no sólo cuantitativa sino cualitativa, no sólo explícita sino también implícita. El ancho y largo espectro de sus producciones, por exposición prolongada, se consolida como uno de los mejores ejemplos de esta paragone entre Poesis y Pictura. La longevidad del artista, contraria a la del poeta, le ha permitido convivir con esos poderes representacionales más tiempo que sus colegas surrealistas. Me estoy refiriendo a Kurt Seligmann, Yves Tanguy, Óscar Domínguez, Kay Sage, René Crevel o Wolffgang Paalen -autores también de corte lautreamontiano- cuya locura se ha materializado en forma de suicidio.

Dicho esto, ya sólo nos queda disfrutar en sala de esta maravillosa pieza, que es la última adquisición de la Fundación Gala-Salvador Dalí. Un estupendo estudio sobre La miel es más dulce que la sangre, que, a no dudar, despertará de nuevo el interés por una obra -aún hoy- poderosa a fuerza de enigmática.

\section{BIBLIOGRAFÍA}

Ades, Dawn, "Estudio para La miel es más dulce que la sangre”, en Dawn Ades (ed.), Dalí, cat. exp., Madrid, La esfera de los libros, 2004a, pp. 90-93.

Ades, Dawn, "El enigma de Hitler", en Dawn Ades (ed.), Dali, cat. exp., Madrid, La esfera de los libros, 2004b, pp. 304-311.

Breton, André, “Introduction”, en Lautréamont, Comte de, Oeuvres Completes, Paris, G.M.L., 1938, pp. 114.

Butazzoni, Fernando, "Luz de arriba, luz de abajo", en Revista Barcarola, Barcelona, n. ${ }^{\text {os }}$ 68-69, noviembre 2006, pp. 181-186.

Cirlot Valenzuela, Lourdes, "Salvador Dalí y sus influencias", en AA. VV., Historiografia i crítica al segle XXI, Barcelona, Universitat de Barcelona, 2004, pp. 11-19. 
Dalí, Salvador, "Moontide”, en Obra Completa de Salvador Dali, vol. III, Barcelona, Destino, Fundación Gala-Salvador Dalí, Sociedad Estatal de Conmemoraciones Culturales, 2003, pp. 1189-1199 (Trad. Hernández, Pau Joan).

Descharnes, Robert, Dali: la obra y el hombre, Barcelona, Tusquets, 1984.

Díaz González, Elisa María, “Aguafuerte y Heliograbado: consideraciones en torno a Les Chants de Maldoror”, en Murphy, Juliette (Comisaria), Salvador Dali. Les Chants de Maldoror. 1934, cat. exp., Figueres, Distribucións d'Art Surrealista, 2010, pp. 145-150.

Fanés, Félix, Salvador Dalí. La construcción de la imagen. 1925-1930, Madrid, Electa, 1999.

Fanés, Félix, "Prólogo", en Dalí, Salvador, Obra Completa de Salvador Dalí, vol. I, Barcelona, Destino, Fundación Gala-Salvador Dalí, Sociedad Estatal de Conmemoraciones Culturales, 2003, pp. 7-43.

Fernández Ruiz, Beatriz, De Rabelais a Dali: la imagen grotesca del cuerpo, Valencia, Universitat de Valencia, 2004.

Fornés, Eduard, Dali y los libros, Barcelona, Caja de Barcelona, 1985.

Gibson, Ian, La vida desaforada de Salvador Dali, Barcelona, Anagrama, 1997.

Gibson, Ian, Lorca-Dali. El amor que no pudo ser, Barcelona, Plaza y Janés, 1999.

Gibson, Ian, Dalí joven, Dali genial, Madrid, Santillana, 2004.

Herrero, Raúl, "Salvador Dalí a golpe de Lautréamont", en Revista Barcarola, Barcelona, n. os 68-69, noviembre 2006, pp. 216-218.

H.H., “Les Chants de Maldoror”, en Dawn Ades (ed.), Dali, cat. exp., Madrid, La esfera de los libros, 2004, pp. 208-219.

Hubert, Renée Riese, Surrealism and the book, Berkeley, University of California Press, 1988.

Lautréamont, Comte de, Les Chants de Maldoror, Paris, Albert Skira, 1934 (dessins de Salvador Dalí).

Lautréamont, Comte de, "Les Chants de Maldoror", en Oeuvres Complètes, Paris, G.M.L., 1938 (Préface de André Breton, dessins de Victor Brauner, Óscar Domínguez, Max Ernst, Agustín Espinoza, René Magritte, André Masson, Joan Miró, Roberto Matta, Wolfgang Paalen, Man Ray, Kurt Seligmann, Yves Tanguy).

Lautréamont, Conde de, "Los cantos de Maldoror", en Obra completa bilingüe, Madrid, Akal, 1988 (Trad. Álvarez Ortega, Manuel).

Mas Peinado, Ricardo, Universo Dali. 30 recorridos por la vida y la obra de Salvador Dali, Barcelona, Lunwerg, 2003.

Moure Pazos, Iván, "Víctimas y verdugos en las ilustraciones de Les Chants de Maldoror de Dalí, en Anuario del departamento de historia y teoría del arte de la universidad autónoma de Madrid, n. ${ }^{\circ}$ 22, 2010, pp. 225-239.

Moure Pazos, Iván, El bestiario del Conde de Lautréamont: la invocación daliniana, Santiago, USC, 2011a.

Moure Pazos, Iván, "Sobre el Conde de Lautréamont y el arte surrealista", en Asociación Aragonesa de Críticos de Arte, n. ${ }^{\circ} 14$, marzo de $2011 \mathrm{~b}, \mathrm{~s} / \mathrm{p}$ (edición electrónica).

Muñoz D’Imbert, Silvia, “Les Chants de Maldoror: la construcción de la máquina de lectura”, en Parcerisas, Pilar (ed.), Dali: afinidades electivas, cat. exp., Barcelona, Fundación Gala-Salvador Dalí, Generalitat de Catalalunya, 2004, pp. 351-415.

Murphy, Juliette, "Les Chants de Maldoror: documentación y proceso creativo", en Murphy, Juliette (Comisaria), Salvador Dalí. Les Chants de Maldoror. 1934, cat. exp., Figueres, Distribucións d'Art Surrealista, 2010, pp. 139-144.

Parcerisas, Pilar, "Introducción”, en Parcerisas, Pilar (ed.), Dali: afinidades electivas, cat. exp., Barcelona, Fundación Gala-Salvador Dalí, Generalitat de Catalalunya, 2004a, pp. 16-47.

Parcerisas, Pilar, "Salvador Dalí y Marcel Duchamp: una partida de ajedrez (con Raymond Roussel, Georges Huguet, André Breton y Man Ray, como voyeaurs)", en Parcerisas, Pilar (ed.), Dalí: afinidades electivas, cat. exp., Barcelona, Fundación Gala-Salvador Dalí, Generalitat de Catalalunya, 2004b, pp. 110190.

Parcerisas, Pilar, "Lautréamont y el magnetismo de los tiempos modernos", en Revista Barcarola, Barcelona, n. ${ }^{\text {os }}$ 68-69, noviembre 2006, pp. 151-154.

Parcerisas, Pilar, Duchamp en España, Madrid, Siruela, 2009.

Parcerisas, Pilar, "Dalí y Ducasse. La sombra de Maldoror", en Murphy, Juliette (Comisaria), Salvador Dalí. Les Chants de Maldoror. 1934, cat. exp., Figueres, Distribucións d'Art Surrealista, 2010, pp. 133-139.

Arch. esp. arte, LXXXv, 338, ABRIL-JUNIO 2012, 181-192, ISSN: 0004-0428 
Pérez Andújar, Javier, Salvador Dalí: a la conquista de lo irracional, Madrid, Algaba, 2003.

Rainwater, Robert, "Au rendez-vous des amis: Surrealist Books and the Beginning of Surrealist Printmaking”, in VV. AA., Visionary States: Surrealist Prints from the Gilbert Kaplan Collection, Los Angeles, University of California, 1997, pp. 23-44.

Ramírez, Juan Antonio, Dali: lo crudo y lo podrido, Madrid, Antonio Machado Libros, 2002.

Rojas, Carlos, El mundo mítico y mágico de Salvador Dalí, Barcelona, Plaza y Janés, 1985.

Sánchez Vidal, Agustín, Buñuel, Lorca, Dalí: el enigma sin fin, Barcelona, Planeta, 1988.

Sánchez Vidal, Agustín, "Introducción”, en Dalí, Salvador, Obra Completa de Salvador Dalí, vol. III, Barcelona, Destino, Fundación Gala-Salvador Dalí, Sociedad Estatal de Conmemoraciones Culturales, 2003, pp. 1-38.

Sánchez Vidal, Agustín, Salvador Dali, Madrid, Fundación MAPFRE, 2007.

Santos Torroella, Rafael, La miel es más dulce que la sangre: las épocas lorquiana y freudiana de Salvador Dali, Barcelona, Seix Barral, 1984.

Santos Torroella, Rafael, El primer Dalí. 1918-1929, Valencia, IVAM y Generalitat Valenciana, 2005.

Fecha de recepción: 5-V-2011

Fecha de aceptación: 10-X-2011 